\title{
Recent Emission Channeling Studies in Wide Band Gap Semiconductors
}

U. WAHL ${ }^{1,2}$, J.G. CORREIA ${ }^{1,2,3}$, E. RITA ${ }^{1,2}$, E. ALVES ${ }^{1,2}$, J.C. SOARES ${ }^{2}$, B. DE VRIES ${ }^{4}$, V. MATIAS ${ }^{4}$, A. VANTOMME ${ }^{4}$, and the ISOLDE collaboration ${ }^{3}$

${ }^{1}$ Instituto Tecnológico e Nuclear, 2685-953 Sacavém, Portugal

${ }^{2}$ Centro de Física Nuclear da Universidade de Lisboa, 1649-003 Lisbon, Portugal

${ }^{3}$ CERN-PH, 1211 Geneva 23, Switzerland

${ }^{4}$ Instituut voor Kern- en Stralingsfysica, 3001 Leuven, Belgium

\begin{abstract}
We present results of recent emission channeling experiments on the lattice location of implanted $\mathrm{Fe}$ and rare earths in wurtzite $\mathrm{GaN}$ and $\mathrm{ZnO}$. In both cases the majority of implanted atoms are found on substitutional cation sites. The root mean square displacements from the ideal substitutional Ga and $\mathrm{Zn}$ sites are given and the stability of the Fe and rare earth lattice location against thermal annealing is discussed.
\end{abstract}

Key words: semiconductors, lattice location, rare earths, Fe doping, implantation.

\section{Introduction}

Wide band gap semiconductors (WBGS) can be roughly defined as semiconductors with an energy gap $E_{\mathrm{G}}$ corresponding to the blue or ultraviolet (UV) range of the optical spectrum, i.e. above $2.5 \mathrm{eV}$. Typical examples are $\mathrm{SiC}\left(E_{\mathrm{G}}=2.4-3.2 \mathrm{eV}\right.$, depending on polytype), $\mathrm{ZnSe}(2.8 \mathrm{eV}), \mathrm{GaN}(3.4 \mathrm{eV}), \mathrm{ZnO}(3.4 \mathrm{eV})$, diamond $(5.5 \mathrm{eV})$, or AlN $(6.2 \mathrm{eV})$. They are all tetrahedrally coordinated and crystallize in the cubic diamond and zinc blende (3C-SiC, $\mathrm{ZnSe}$ ), or hexagonal wurtzite $(2 \mathrm{H}-\mathrm{SiC}$, $\mathrm{GaN}, \mathrm{AlN}, \mathrm{ZnO}$ ) and related hexagonal (e.g. 4H-SiC) structures.

There exist already many technological applications for WBGS, such as light emitting diodes or lasers in the blue and UV [1,2], visible-blind detectors for UV light [1-3], high-temperature high-power transistors [1,2,4], or gas sensors [5,6]. Recently, WBGS have also emerged as candidates for multiple-color electroluminescent devices [7] suitable for displays, and in the field of spintronics [8]. Both cases are based on the incorporation of impurities, either rare earth (RE) elements as optical dopants, or $3 d$ transition metals (TM) such as $\mathrm{Cr}, \mathrm{Mn}, \mathrm{Fe}$, Co or Ni as ferromagnetic dopants. In the case of RE doping, an empirical rule was established [9] that the quenching of the RE luminescence at room temperature is less pronounced in semiconductors with a wide band gap. The major quest in order to realize spintronic devices is to find semiconductors which exhibit ferromagnetism at or above room temperature, and theoretical considerations predict the diluted magnetic semiconductors $\mathrm{Ga}_{1-\mathrm{x}} \mathrm{TM}_{\mathrm{x}} \mathrm{N}$ and $\mathrm{Zn}_{1-\mathrm{x}} \mathrm{TM}_{\mathrm{x}} \mathrm{O}$ and TM-doped diamond to be most promising for that purpose $[10,11]$.

A crucial point with regards to any kind of doping in semiconductors, electrical, optical or magnetic, is the activation of the dopants. Not only is it required to incorporate the dopants into the appropriate lattice sites but also to control possible inter-

Corresponding author: U. Wahl, Instituto Tecnológico e Nuclear, Dep. Física, Estrada Nacional 10, 2686-953 Sacavém, Portugal, phone: 00351-21-9946085, fax: 00351-21-9941525, email: uwahl@itn.pt 
actions with additional crystal defects. The successful implementation of ion implantation as a means of doping would considerably enhance the possibilities of WBGS technology and is currently an active field of research $[2,4,12]$ but faces some inherent problems. While high resistance against the formation of radiation damage is a common feature of WBGS, due to the fact that a large band gap is correlated with strong atomic bonds, it is on the other hand extremely difficult to anneal defects once they have been created. Crystal defects and their interaction with dopants are therefore of particular relevance in these materials.

While the emission channeling method provides direct information on the lattice sites of implanted impurities, hyperfine interaction methods such as Mössbauer spectroscopy (MS) or the perturbed angular correlation (PAC) techniques are in many cases suitable in order to investigate the local environment around probe atoms and can hence be applied in a complementary way. Although our group is engaged in lattice location studies of a broad range of implanted impurities in a number of WBGS, mainly GaN, AlN, ZnO, diamond, and recently also SiC, we will present here only the cases of RE and Fe impurities in $\mathrm{GaN}$ and $\mathrm{ZnO}$, since they are of particular relevance with respect to the applications mentioned above and also accessible to investigation by hyperfine interaction techniques. Apart from $\mathrm{GaN}$ and $\mathrm{ZnO}$ there have also been emission channeling experiments reported on $\mathrm{Fe}$ in diamond [13], rare earths in InGaN [14], AlN [15], SiC [16] and cubic BN [17].

There exist a number of RE probe nuclei whose applicability for Mössbauer studies has been discussed, e.g. ${ }^{141} \mathrm{Pr},{ }^{149} \mathrm{Sm},{ }^{151} \mathrm{Eu},{ }^{155} \mathrm{Gd},{ }^{161} \mathrm{Dy},{ }^{166} \mathrm{Er},{ }^{169} \mathrm{Tm}$ and ${ }^{170} \mathrm{Yb}$ [18-20]. However, except for the work of Masterov et al on ${ }^{169} \mathrm{Tm}$ in amorphous Si [21], almost nothing has been published on MS from rare earth probes in semiconductors. Likewise, RE are not among the most common PAC probes, but some applications on the study of electric field gradients of ${ }^{160} \mathrm{Dy},{ }^{169} \mathrm{Tm}$, and ${ }^{172} \mathrm{Yb}$ in metals have been reported [22-25], and first studies on ${ }^{172} \mathrm{Yb}$ PAC in WBGS [26] are being presented at this conference. Quite some experimental work has been done on Mössbauer effect of ${ }^{57} \mathrm{Fe}$ in semiconductors, including absorber experiments and source experiments from the decay of ${ }^{57} \mathrm{Mn}$ or ${ }^{57} \mathrm{Co}$ or following Coulomb excitation of ${ }^{57} \mathrm{Fe}$ [27-29]. Investigations on wide band gap semiconductors, however, are found scarcer, with diamond being the best studied host [30] and only a small number of experiments reported on $\mathrm{ZnO}[31,32]$ and $\mathrm{GaN}$ [33].

\section{Method}

The electron emission channeling method makes use of the fact that $\beta^{-}$particles and conversion electrons emitted from radioactive isotopes in a single crystal experience channeling or blocking effects that depend characteristically on the lattice site(s) of the emitter atom. Several reviews on emission channeling can be found in the literature [34-37].

Corresponding author: U. Wahl, Instituto Tecnológico e Nuclear, Dep. Física, Estrada Nacional 10, 2686-953 Sacavém, Portugal, phone: 00351-21-9946085, fax: 00351-21-9941525, email: uwahl@itn.pt 


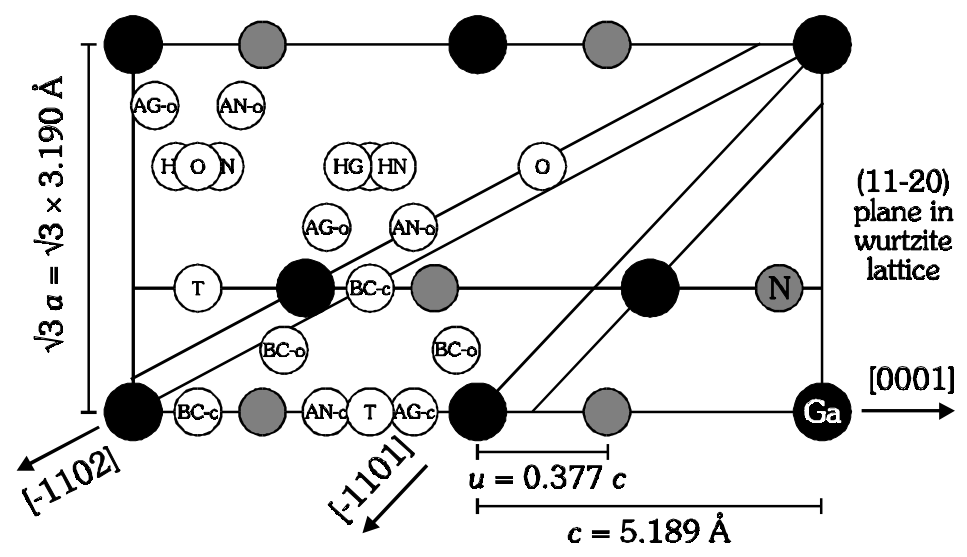

Figure 1. The (1120) plane in the GaN wurtzite lattice, showing the $\mathrm{Ga}$ and $\mathrm{N}$ lattice positions and some of the possible interstitial sites; "-c" denotes sites within and "-o" off the $c$-axis.

The production of radioisotopes and implantation into single-crystalline $\mathrm{ZnO}$ and thin film GaN samples at $60 \mathrm{keV}$ and fluences around $1-3 \times 10^{13} \mathrm{~cm}^{-2}$ was done at CERN's ISOLDE facility [38,39]. A position-sensitive electron detector was used in order to measure the angle-dependent electron emission yield around various crystallographic directions [40]. Quantitative results were achieved by comparing the experimental data with theoretical patterns calculated by means of the "manybeam" formalism [34-37] for a wide range of possible lattice sites. The fitting procedures used for that purpose have been described in detail previously [37,40].

Examples for possible lattice sites of higher symmetry in the $\mathrm{GaN}$ wurtzite structure are shown in Fig. 1, including substitutional $\mathrm{Ga}\left(\mathrm{S}_{\mathrm{Ga}}\right)$ and $\mathrm{N}\left(\mathrm{S}_{\mathrm{N}}\right)$ sites, bondcentered (BC) and anti-bonding ( $\mathrm{AB}$ ) sites both within and off the $c$-axis, the "hexagonal" sites $\mathrm{HG}$ and $\mathrm{HN}$, and the so-called $\mathrm{T}$ - and $\mathrm{O}$-sites [41]. With respect to hyperfine interaction studies it is worth while to point out that in an ideal wurtzite structure (i.e. with $c / a=1.633$ and $c$-axis bond length parameter $u=0.375 c$ ) the symmetry of the intact first atomic neighbour shells around perfect $\mathrm{S}_{\mathrm{Ga}}$ and $\mathrm{S}_{\mathrm{N}}$ positions is tetrahedral cubic $\left(T_{\mathrm{d}}\right)$. Hence impurities in substitutional positions experience comparably small electrical field gradients which are mainly due to the non-cubic $2^{\text {nd }}$ nearest neighbour shell or non-ideal $u$ parameters. Lattice sites along the $c$-axis (e.g. T, BC-c) and along the main interstitial axis parallel to the $c$-axis (e.g. O, HG, $\mathrm{HN})$ possess strict trigonal $\left(C_{3 \mathrm{v}}\right)$ symmetry, while all sites off these axes are of lower symmetry.

\section{Results}

\subsection{FE IN GAN AND ZNO}

As an example, Figs. 2 (a)-(d) show the $\beta^{-}$emission channeling patterns from ${ }^{59} \mathrm{Fe}$ in $\mathrm{ZnO}$, directly following room temperature implantation. The theoretical patterns 
resulting from the best two-fraction fits are shown in Fig. (e)-(h). They were obtained by considering only $\mathrm{Fe}$ on substitutional $\mathrm{S}_{\mathrm{Zn}}$ sites and varying its root mean square (rms) displacement $u_{1}(\mathrm{Fe})$, and Fe on random sites. Note that the random fraction accounts for Fe atoms on sites contributing with an isotropic emission yield, which are sites of very low crystal symmetry or in heavily damaged surroundings. In the as-implanted state, the ${ }^{59} \mathrm{Fe}$ rms displacements from $\mathrm{S}_{\mathrm{Zn}}$ sites which gave the best fit were $0.16 \AA, 0.12 \AA, 0.10 \AA$ and $0.11 \AA$, perpendicular to the [0001], [1102], [1101] and [2113] directions, respectively, and the corresponding fractions on $\mathrm{S}_{\mathrm{Zn}}$ sites were $108 \%, 84 \%, 84 \%$ and $81 \%$.

(a) $[0001]$
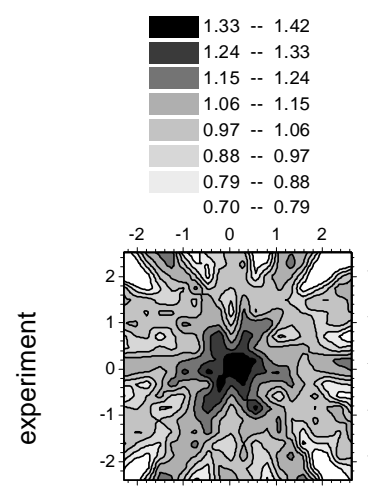

(b) $[1102]$
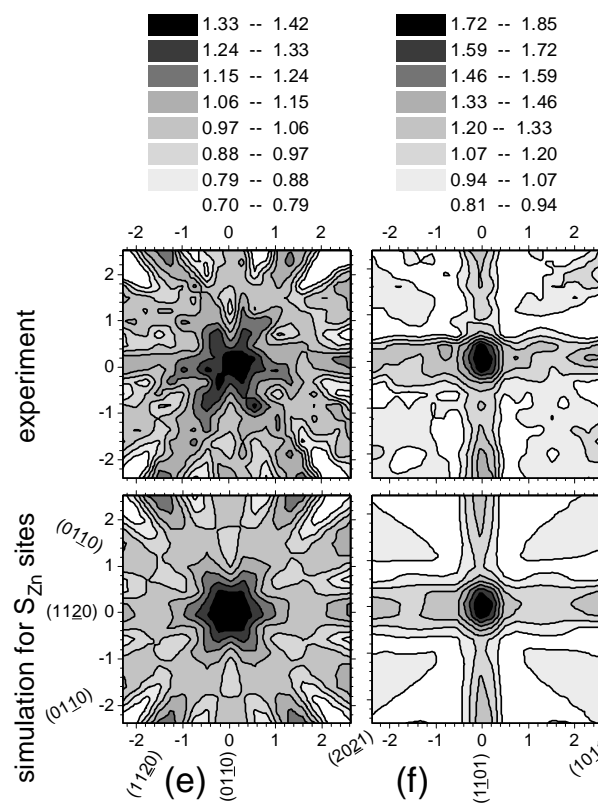

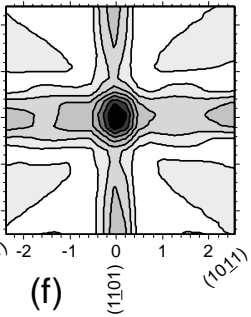

(f) (c) $[1101]$

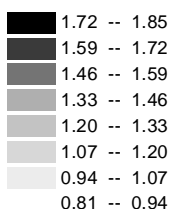

$\begin{array}{lllll}-2 & -1 & 0 & 1 & 2\end{array}$
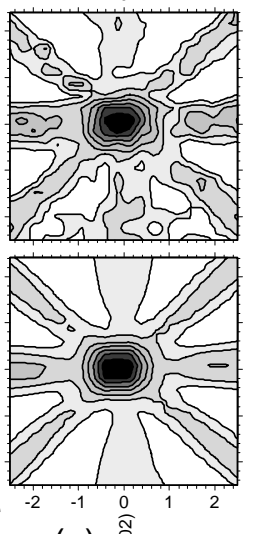

(g) $\stackrel{\widehat{\widetilde{o}}}{=}$ (d) [2113]

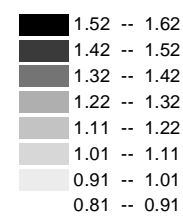

$\begin{array}{lll}-2 & -1 & 0\end{array}$
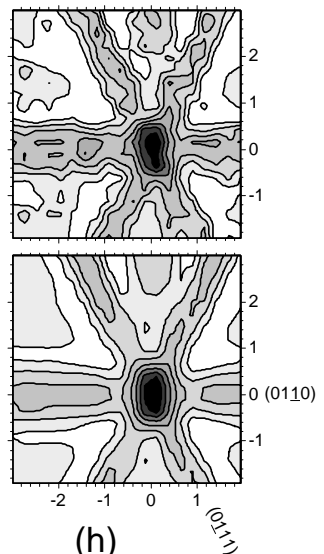

Figure 2. Angular distribution of $\beta^{-}$emission yields from ${ }^{59} \mathrm{Fe}$ in $\mathrm{ZnO}$ in the as-implanted state. The best fits of the channeling patterns for each direction are also shown, yielding an average of $89(11) \%$ of Fe atoms at $\mathrm{S}_{\mathrm{Zn}}$ sites.

Figure 3 compares the Fe fractions on substitutional cation sites and their rms displacements as a function of annealing temperature for $\mathrm{GaN}$ [42] and $\mathrm{ZnO}$. In both cases $80-90 \%$ of $\mathrm{Fe}$ atoms were found on $\mathrm{S}_{\mathrm{Ga}}$ or $\mathrm{S}_{\mathrm{Zn}}$ sites already in the as-implanted state, but with rms displacements exceeding the thermal vibration amplitude of the $\mathrm{Ga}$ or $\mathrm{Zn}$ atoms by up to a factor of two. In $\mathrm{GaN}$, annealing up to $900^{\circ} \mathrm{C}$ practically did not change this situation. In $\mathrm{ZnO}$, on the other hand, the $800^{\circ} \mathrm{C}$ anneal induced a significant decrease in the Fe rms displacements, reducing them to more or less the same values as expected for the $\mathrm{Zn}$ host atoms. Apart from the random fractions we found no evidence for ${ }^{59} \mathrm{Fe}$ located at other lattice sites than $\mathrm{S}_{\mathrm{Zn}}$ or $\mathrm{S}_{\mathrm{Ga}}$, respectively.

Corresponding author: U. Wahl, Instituto Tecnológico e Nuclear, Dep. Física, Estrada Nacional 10, 2686-953 Sacavém, Portugal, phone: 00351-21-9946085, fax: 00351-21-9941525, email: uwahl@itn.pt 


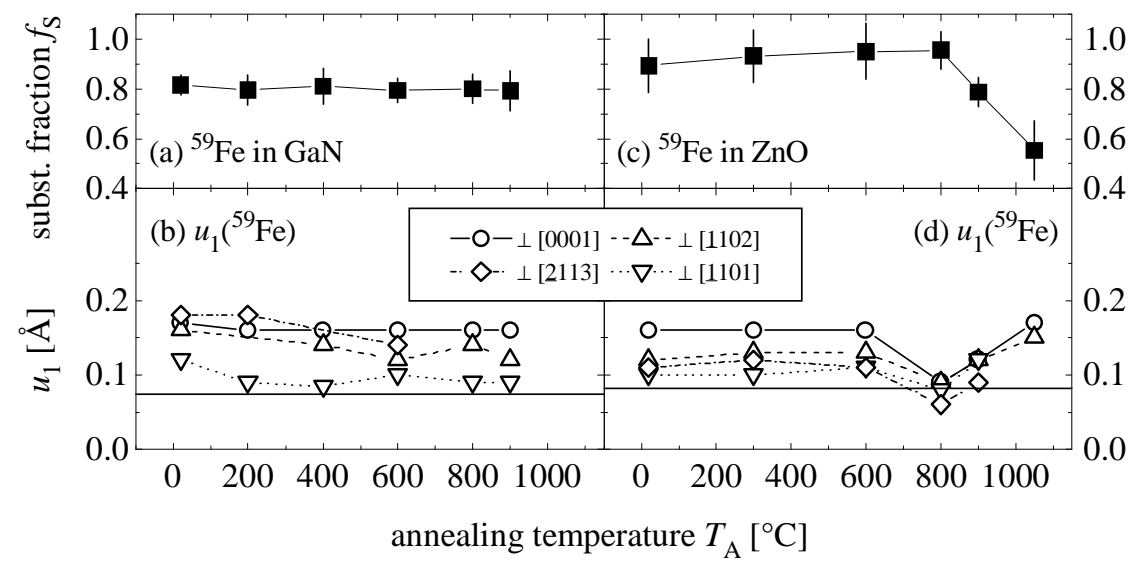

Figure 3. Fraction of Fe atoms on substitutional cation sites in $\mathrm{GaN}$ (a) and $\mathrm{ZnO}$ (c) and their rms displacements (b, d) following thermal annealing (up to $900^{\circ} \mathrm{C}$ for $10 \mathrm{~min}$ in vacuum, the $1050^{\circ} \mathrm{C}$ step for $\mathrm{ZnO}$ was $30 \mathrm{~min}$ in air). The straight lines indicate the room temperature rms displacements of $\mathrm{Ga}$ and $\mathrm{Zn}$ atoms, respectively.

The high substitutional fractions illustrate that the implantation damage in both materials was low, while rms displacements exceeding those of the host atoms can be explained by slight displacements of Fe atoms due to the presence of nearby defects. The fact that annealing of the $\mathrm{ZnO}$ sample at $800^{\circ} \mathrm{C}$ resulted in perfect substitutional incorporation of $\mathrm{Fe}$ shows that it is possible to remove most of the damage in this material following low fluence implantation, in contrast to $\mathrm{GaN}$, where the only visible effect of annealing was a slight decrease in the Fe rms displacements. In $\mathrm{ZnO}$, annealing at $900^{\circ} \mathrm{C}$ and $1050^{\circ} \mathrm{C}$ caused the $\mathrm{Fe}$ rms displacements to increase again, accompanied by a significant decrease in the fraction on $\mathrm{S}_{\mathrm{Zn}}$ sites. This indicates that the high temperature annealing has introduced crystal defects in the nearsurface layers, which can interact with the Fe atoms, causing them to occupy displaced substitutional positions or random sites.

\subsection{RARE EARTHS IN NITRIDES AND ZNO}

The first emission channeling experiments on RE-implanted GaN were done by Dalmer et al. [43] who examined the conversion electrons emitted by ${ }^{167 \mathrm{~m}} \mathrm{Er}$ resulting from the decay of ${ }^{167} \mathrm{Tm}$ and by ${ }^{169 *} \mathrm{Tm}$ resulting from ${ }^{169} \mathrm{Yb}$. However, only $c$ axis angular scans were compared to simulations, with the best fits obtained for 90(10)\% of RE atoms on sites showing displacements of $0.25 \AA$ from the $c$-axis, both in the as-implanted state and following annealing at $800^{\circ} \mathrm{C}$.

Corresponding author: U. Wahl, Instituto Tecnológico e Nuclear, Dep. Física, Estrada Nacional 10, 2686-953 Sacavém, Portugal, phone: 00351-21-9946085, fax: 00351-21-9941525, email: uwahl@itn.pt 

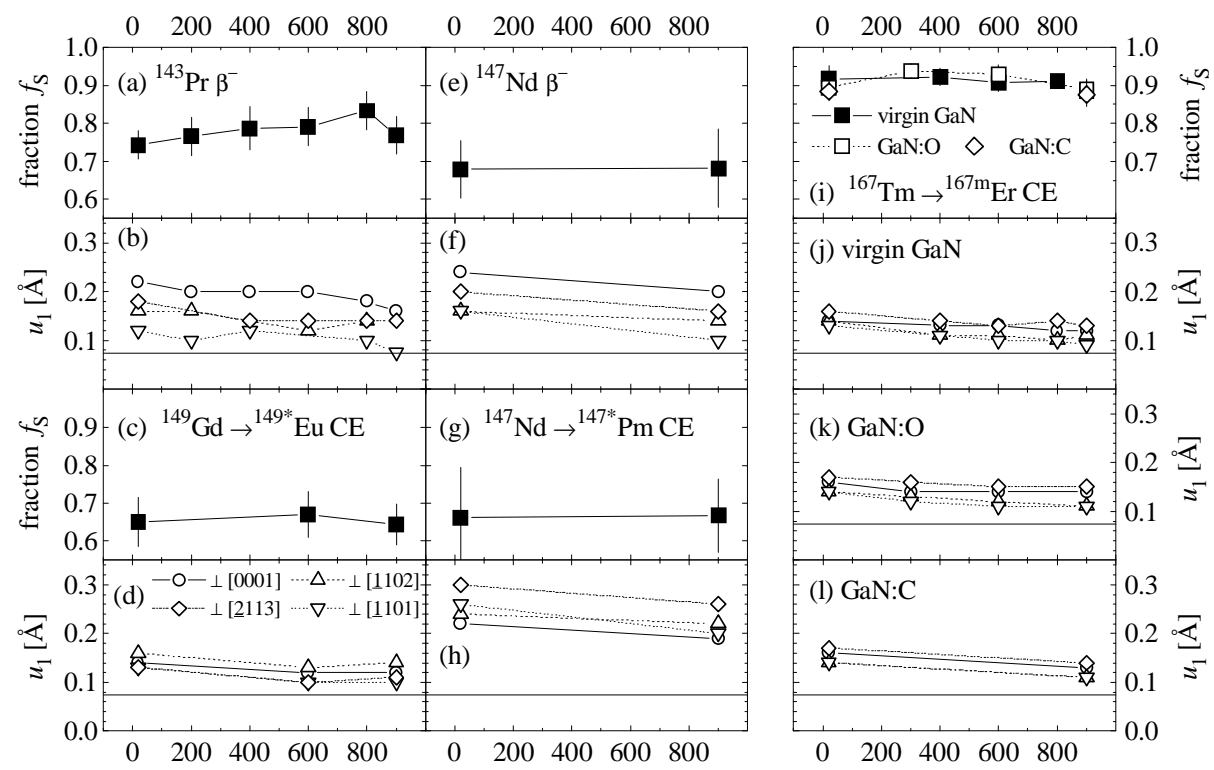

annealing temperature $\left[{ }^{\circ} \mathrm{C}\right]$

Figure 4. Fractions on substitutional Ga sites and rms displacements as function of annealing temperature for various rare earth probe isotopes in $\mathrm{GaN}$.

More recently we have done emission channeling experiments using the $\beta^{-}$particles from ${ }^{143} \operatorname{Pr}[41,44]$ and the conversion electrons (CE) emitted by ${ }^{149} * \mathrm{Eu}$ following the decay of ${ }^{149} \mathrm{Gd}[44,45]$. In addition we used the isotope ${ }^{147} \mathrm{Nd}$, which allows to do lattice location studies of both the $\beta^{-}$emitting mother ${ }^{147} \mathrm{Nd}$ and $\mathrm{CE}$ emitting daughter ${ }^{147 *} \mathrm{Pm}[44,46]$. An additional experiment with CE from ${ }^{167 \mathrm{~m}} \mathrm{Er}$ was done on virgin GaN and GaN co-implanted with $\mathrm{O}$ or $\mathrm{C}$ [47].

In all cases the majority of RE atoms (around 65-95\%) were found on substitutional Ga sites (Fig. 4), the substitutional fractions being highest in the case of ${ }^{143} \mathrm{Pr}$ and ${ }^{167} \mathrm{Tm} \rightarrow{ }^{167 \mathrm{~m}} \mathrm{Er}$, and lower for ${ }^{147} \mathrm{Nd},{ }^{147} \mathrm{Nd} \rightarrow{ }^{147 *} \mathrm{Pm}$ and ${ }^{149} \mathrm{Gd} \rightarrow{ }^{149 *} \mathrm{Eu}$. Whereas the rms displacements from the $\mathrm{S}_{\mathrm{Ga}}$ sites decreased with annealing temperature, the substitutional fractions hardly changed following 10-min annealing sequences up to $900^{\circ} \mathrm{C}$ under vacuum. Variations in the rms displacements perpendicular to the four different channeling directions for each experiment and from isotope to isotope could indicate that different rare earth atoms experience small static displacements along well-defined crystallographic directions. However, more experiments with additional isotopes will be needed to confirm whether there are systematic trends in that respect. Note that in the conversion electron experiments we have so far not found any indication that there are major changes in the lattice sites due to nuclear recoil or after-effects from radioactive decay.

Corresponding author: U. Wahl, Instituto Tecnológico e Nuclear, Dep. Física, Estrada Nacional 10, 2686-953 Sacavém, Portugal, phone: 00351-21-9946085, fax: 00351-21-9941525, email: uwahl@itn.pt 
It has been reported in the literature that co-doping with $\mathrm{O}$ or $\mathrm{C}$ enhances the $\mathrm{RE}$ luminescence in $\mathrm{GaN}$ [48] and it is known that the formation of complexes between $\mathrm{O}$ and Er changes the lattice location of $\mathrm{Er}$ in $\mathrm{Si}$ [49]. We therefore also investigated the lattice sites of ${ }^{167 \mathrm{~m}} \mathrm{Er}$ in two GaN samples that were pre-implanted with $\mathrm{O}$ and $\mathrm{C}$. Our results [Fig. 4 (i)-(k)] show that the presence of $\mathrm{O}$ and $\mathrm{C}$, even if it exceeds the $\mathrm{RE}$ concentration by a factor of 14 , has no effect on the lattice site of ${ }^{167 \mathrm{~m}} \mathrm{Er}$ in GaN [47].

In $\mathrm{ZnO}$ the rare earths showed a somewhat different behaviour. As in GaN, already immediately following implantation $75-100 \%$ of $\mathrm{RE}$ atoms occupied cation $\mathrm{Zn}$ sites. However, $600-700^{\circ} \mathrm{C}$ annealing resulted in a significant decrease of the rms displacements of both ${ }^{167 \mathrm{~m}} \operatorname{Er}$ [50] and ${ }^{169^{*}} \mathrm{Tm}$ probes [51], while for higher annealing temperatures the substitutional RE fractions decreased and their rms displacements increased again, even more pronounced than in the case of Fe. It is known from Rutherford backscattering experiments on higher-dose implanted samples that $\mathrm{Er}$ atoms in $\mathrm{ZnO}$ diffuse around $1050^{\circ} \mathrm{C}$ [52]. Hence it seems possible that in our case short-range RE diffusion may have contributed to some extent in its pairing with other defects at $800-900^{\circ} \mathrm{C}$.

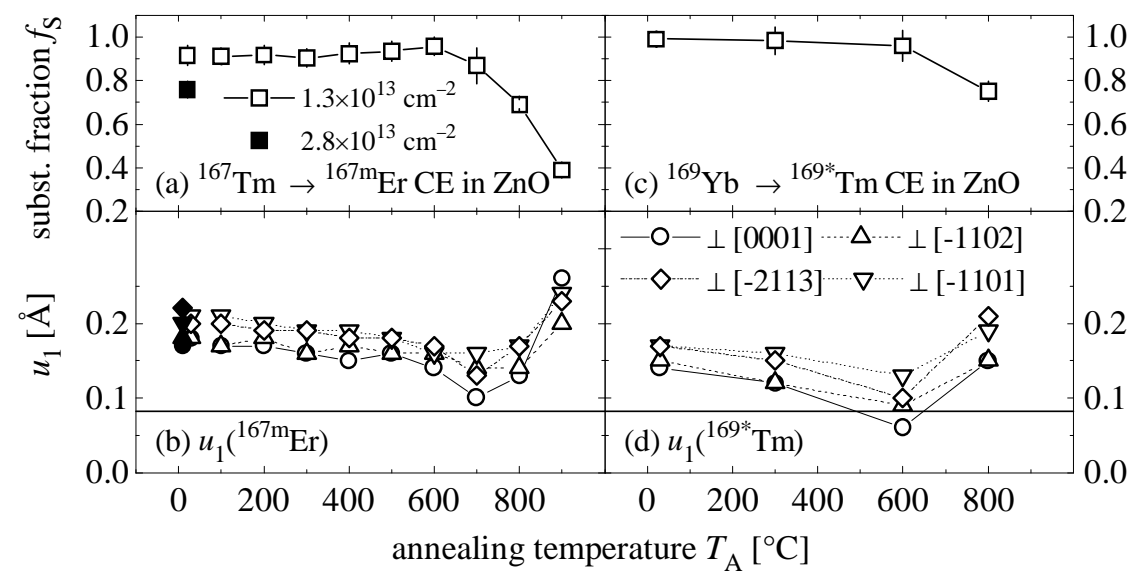

Figure 5. Fractions on $\mathrm{Zn}$ sites as a function of annealing temperature for ${ }^{167 \mathrm{~m}} \mathrm{Er}$ (a) and ${ }^{169^{*}} \mathrm{Tm}$ (c) in $\mathrm{ZnO}$ and corresponding rms displacements (b), (d). All annealings were for $10 \mathrm{~min}$ in vacuum, except for the $800^{\circ} \mathrm{C}$ step in (c) and (d), which was under flowing $\mathrm{O}_{2}$.

\section{Conclusions}

Following low dose implantations $\left(1-3 \times 10^{13} \mathrm{~cm}^{-2}\right)$ of Fe and rare earth elements into $\mathrm{GaN}$ and $\mathrm{ZnO}$, the majority of the implants occupy substitutional cation sites. However, rms displacements which are substantially larger than those of the host atoms indicate that there are defects present in the immediate neighbourhood of the implanted probes. In GaN, only small reductions in the impurity rms displacements

Corresponding author: U. Wahl, Instituto Tecnológico e Nuclear, Dep. Física, Estrada Nacional 10, 2686-953 Sacavém, Portugal, phone: 00351-21-9946085, fax: 00351-21-9941525, email: uwahl@itn.pt 
were observed up to $900^{\circ} \mathrm{C}$, showing that a substantial part of them remains in distorted $\mathrm{Ga}$ sites. In $\mathrm{ZnO}$ best incorporation on substitutional $\mathrm{Zn}$ sites was obtained after $800^{\circ} \mathrm{C}$ annealing for $\mathrm{Fe}$ and $600-700^{\circ} \mathrm{C}$ annealing for $\mathrm{RE}$ elements. At higher annealing temperatures, the probe atoms experience again increased levels of disorder. The mechanism of this is not yet entirely clear but probably involves the formation of defect complexes as a result of defect creation in near surface layers during annealing and/or short-range diffusion of the implanted species.

We would like to point out that some of the open questions with respect to RE and TM impurities in wide band gap semiconductors are accessible to hyperfine interaction techniques. As it is clear from our studies, following ion implantation the trapping of defects by RE or Fe and the annealing of defect complexes should be observable. It has been proposed that defects play an important role in the luminescence excitation of RE in GaN [53], which begs for an assessment of crystal defects in the RE neighbourhood. In a similar way, it has been pointed out [Pearton 03a] that more information is needed on the microstructure of TM-related defects in diluted magnetic semiconductors in order to explain the nature of the observed magnetism and the possible role of second phases.

\section{Acknowledgments}

This work was funded by the FCT, Portugal (project POCTI-FNU-49503-2002) and by the European Union (Large Scale Facility contract HPRI-CT-1999-00018). U. Wahl and E. Rita acknowledge their fellowships supported by the FCT, Portugal.

\section{References}

1. $\quad$ S.N. Mohammad and H. Morkoç, Prog. Quant. Electr. 20 (1996) 361.

S.J. Pearton, J.C. Zolper, R.J. Shul, and F. Ren, J. Appl. Phys. 86 (1999) 1

E. Monroy, F. Omnès, and F. Calle, Semicond. Sci. Technol. 18 (2003) R33.

S.J. Pearton, F. Ren, A.P. Zhang, and K.P. Lee, Mater. Sci. Eng. R 30 (2000) 55

D. Kohl, J. Phys. D: Appl. Phys. 34 (2001) R125.

6. S.J. Pearton, B.S. Kang, S. Kim, F. Ren, B.P. Gila, C.R. Abernathy, J. Lin, and S.N.G. Chu, J. Phys.: Condens. Matter 16 (2004) R961.

7. A.J. Steckl and J.M. Zavada, Mater. Res. Soc. Bulletin 24 (1999) 23.

8. S.J. Pearton, C.R. Abernathy, M.E. Overberg, G.T. Thaler, D.P. Norton, N. Theodoropoulou, A.F. Hebard, Y.D. Park, F. Ren, J. Kim, and L.A. Boatner, J. Appl. Phys. 93 (2003) 1.

9. P.N. Favennec, H. L'Haridon, D. Moutonnet, M. Salvi, and M. Gauneau, Mater. Res. Soc. Symp. Proc. 301 (1993) 181.

10. T. Dietl, Semicond. Sci. Technol. 17 (2002) 377.

11. K. Sato and H. Katayama-Yoshida, Hyp. Int. 136 (2001) 737.

12. S.O. Kucheyev, J.S. Williams, C. Jagadish, J. Zou, C. Evans, A.J. Nelson, and A.V. Hamza, Phys. Rev. B 67 (2003) 094115.

13. K. Bharuth-Ram, U. Wahl, and J.G. Correia, Nucl. Instr. Meth. B 206 (2003) 941.

14. E. Alves, R. Correia, S. Pereira, U. Wahl, B. De Vries, and A. Vantomme, Nucl. Instr. Meth. B 206 (2003) 1042

15. U. Vetter, M.F. Reid, H. Hofsäss, C. Ronning, J. Zenneck, M. Dietrich, and the ISOLDE Collaboration, Mat. Res. Soc. Symp. Proc. 743 (2003) L 6.16.

16. U. Vetter, H. Hofsäss, U. Wahl, M. Dietrich, and the ISOLDE collaboration, Diamond and Related Materials12 (2003) 1883

Corresponding author: U. Wahl, Instituto Tecnológico e Nuclear, Dep. Física, Estrada Nacional 10, 2686-953 Sacavém, Portugal, phone: 00351-21-9946085, fax: 00351-21-9941525, email: uwahl@itn.pt 
17. U. Vetter, T.Taniguchi, U.Wahl, J.Correia, A. Müller, C. Ronning, H.Hofsäss, M. Dietrich, and the ISOLDE Collaboration, Mat. Res. Soc. Symp. Proc. 744 (2003) M 8.38.

18. G.A. Stewart, Materials Forum 18 (1994) 177.

19. M. Dalmer, U. Vetter, M. Restle, A. Stötzler, H. Hofsäss, C. Ronning, M.K. Moodley, K. BharuthRam, and the ISOLDE collaboration, Hyp. Int. 120 (1999) 347.

20. J.M. Cadogan and D.H. Ryan, Hyp. Int. 153 (2004) 25.

21. V.F. Masterov, F.S. Nasredinov, P.P. Seregin, V.K. Kudoyarova, A.N. Kuznetsov, and. E.I. Terukov, Appl. Phys. Lett. 72 (1998) 728.

22. R.L. Rasera and A. Li-Scholz, Phys. Rev. B 1 (1970) 1995.

23. L. Thomé, H. Bernas, F. Abel, M. Bruneaux, C. Cohen, and J. Chaumont, Phys. Rev. B. 14 (1976) 2787.

24. R. Dogra, A.K. Bhati, and S.C. Bedi, Hyp. Int. 108 (1997) 515.

25. R. Vianden, Hyp. Int. 35 (1987) 1079.

26. R. Nédélec, R. Vianden, and the ISOLDE collaboration, this conference, contr. C.7

27. P. Schwalbach, S. Laubach, M. Hartick, E. Kankeleit, B. Keck, M. Menningen, and R. Sielemann, Phys. Rev. Lett. 64 (1990) 1274.

28. G. Langouche, Hyperfine Interactions 72 (1992) 217.

29. G. Weyer and the ISOLDE collaboration, Hyp. Int. 129 (2000) 371.

30. K. Bharuth-Ram, Hyp. Int. 151 (2003) 21.

31. G.F. Goya, S.J. Stewart, and R.C. Mercader, Sol. State. Comm. 96 (1995) 485.

32. G.F. Goya, and E.R. Leite, J. Phys: Condens. Matter 15 (2003) 641.

33. E. Alves, C. Liu, J.C. Waerenborgh, M.F. Da Silva, and J.C. Soares, Nucl. Instr. Meth. B 175 (2001) 241.

34. H. Hofsäss, G. Lindner, Phys. Rep. 210 (1991) 121.

35. H. Hofsäss, U. Wahl and S.G. Jahn, Hyp. Int. 84 (1994) 27.

36. H. Hofsäss, Hyp. Int. 97 (1996) 247.

37. U. Wahl, Hyp. Int. 129 (2000) 349.

38. E. Kugler, Hyp. Int. 129 (2000) 23.

39. M. Deicher, G. Weyer, T. Wichert, and the ISOLDE collaboration, Hyp. Int. 151 (2003) 105.

40. U. Wahl, J.G. Correia, A. Czermak, S.G. Jahn, P. Jalocha, J.G. Marques, A. Rudge, F. Schopper, A. Vantomme, P. Weilhammer, and the ISOLDE collaboration Nucl. Instr. Meth. A 524 (2004) 245.

41. U. Wahl, A. Vantomme, G. Langouche, J.P. Araujo, L. Peralta, G. Correia, the ISOLDE collaboration, J. Appl. Phys. 88 (2000) 1319.

42. U. Wahl, A. Vantomme, G. Langouche, J.G. Correia, L. Peralta, and the ISOLDE collaboration, Appl. Phys. Lett. 78 (2001) 3217.

43. M. Dalmer, M. Restle, A. Stötzler, U. Vetter, H. Hofsäss, M.D. Bremser, C. Ronning, R.F. Davies, Mat. Res. Soc. Symp. Proc. 482 (1998) 1021.

44. U. Wahl, E. Alves, K. Lorenz, J.G. Correia, T. Monteiro, B. De Vries, A. Vantomme, and R. Vianden, Mater. Sci. Eng. B 105 (2003) 132.

45. B. De Vries, U. Wahl, A. Vantomme, J.G. Correia, and the ISOLDE collaboration, Mater. Sci. Eng. B 105 (2003) 106.

46. B. De Vries, U. Wahl, A. Vantomme, J.G. Correia, and the ISOLDE collaboration, phys. stat. sol. (c) 0 (2002) 453.

47. B. De Vries, V. Matias, A. Vantomme, U. Wahl, E.M.C. Rita, E.Alves, A.M.L. Lopes, J.G. Correia, and the ISOLDE collaboration, Appl. Phys. Lett. 84 (2004) 4304

48. J.T. Torvik, C.H. Qiu, R.J. Feuerstein, J.I. Pankove, and F. Namavar, J. Appl. Phys. 81 (1997) 6343.

49. U. Wahl, A. Vantomme, J. De Wachter, R. Moons, G. Langouche, J.G. Marques, J.G. Correia, and the ISOLDE collaboration, Phys. Rev. Lett. 79 (1997) 2069.

50. U. Wahl, E. Rita, E. Alves, J.G. Correia, J.P. Araújo, and the ISOLDE collaboration, Appl. Phys. Lett. 82 (2003) 1173.

51. E.M.C. Rita, U. Wahl, A.L. Lopes, J.P. Araújo, J.G. Correia, E. Alves, J.C. Soares, and the ISOLDE collaboration, Mat. Res. Soc. Symp. Proc. 774 (2003) M 3.7.

52. E. Alves, E. Rita, U. Wahl, J.G. Correia, T. Monteiro, and C. Boemare, Nucl. Instr. Meth. B 206 (2003) 1047

53. A. Braud, J.L. Doualan, R. Moncorge, B. Pipeleers, and A. Vantomme, Mater. Sci. Eng. B 105 (2003) 101.

Corresponding author: U. Wahl, Instituto Tecnológico e Nuclear, Dep. Física, Estrada Nacional 10, 2686-953 Sacavém, Portugal, phone: 00351-21-9946085, fax: 00351-21-9941525, email: uwahl@itn.pt 